\title{
Pleural amyloidosis presenting as recurrent bilateral pleural effusions
}

\author{
Anthony Tran ${ }^{1}$, Ahna M. Blutreich ${ }^{2}$, Alicia McKelvey ${ }^{1}$ \\ ${ }^{1}$ Department of Thoracic Surgery, ${ }^{2}$ Department of Pathology, Hartford Hospital, Hartford, CT, USA \\ Correspondence to: Dr. Alicia McKelvey, MD, FACS. Division of General Thoracic Surgery, Hartford Hospital, 85 Seymore Street, ste 227, Hartford, \\ CT 06106, USA. Email: Alicia.McKelvey@hhchealth.org.
}

\begin{abstract}
Amyloidosis is a disease of insoluble protein deposition. It can affect many organ systems but less commonly found in the lung. Pleural effusions secondary to amyloidosis are rare and sparsely reported in the literature. The incidence ranges from 9 to 14 per million person-years. We present a case report of a 77-yearold female with respiratory distress and recurrent bilateral pleural effusions and known intra-abdominal amyloidosis. Initially, we attempted conservative non-operative management using tube thoracostomy drainage with lytic medications. But ultimately, she required decortication with the hope of promoting symphysis of her lung and chest wall to prevent recurrent effusions. Further investigation is warranted in this disease process, as the exact mechanism remains elusive. The same holds true regarding a standardized treatment approach due to the rarity of the disease.
\end{abstract}

Keywords: Pleural amyloidosis; effusion; video-assisted thoracoscopy; amyloidosis

Received: 09 May 2019; Accepted: 27 May 2019; published: 17 June 2019.

doi: $10.21037 /$ ccts.2019.05.03

View this article at: http://dx.doi.org/10.21037/ccts.2019.05.03

\section{Introduction}

Amyloidosis is a disease resulting in extra-cellular deposition of insoluble protein that typically possesses an apple-green birefringence with polarized light and positive Congo red staining. Electron microscopic assessment of these proteins in the late 1950s revealed that they were actually fibrils. Once deposited, they can result in organ dysfunction. There are several types of amyloid deposits with the most common being AL (immunoglobulin light chain fragments) and AA (serum amyloid A). The disease is rare, with an incidence ranging from 9 to 14 cases per million person-years (1). The incidence of persistent pleural effusions secondary to systemic amyloidosis or even more rare, as it has only been described in $6 \%$ of patients with systemic amyloidosis from a high-volume amyloidosis center (2). Given how uncommon it is, the exact classification and treatment remains elusive. We add to the body of literature of pleural amyloid deposition resulting in persistent pleural effusions, mimicking a malignant mesothelioma.

\section{Case presentation}

A 77-year-old female presented with hypoxia and pleuritic chest pain secondary to recurrent bilateral pleural effusions. Her past medical history is significant for B-cell lymphoma, small lymphocytic lymphoma, temporal arteritis, trisomy 12, and intra-abdominal amyloidosis (AL-Kappa type). She was known to our surgical service as she had a videoassisted thoracoscopic (VATS) right partial decortication and wedge biopsy along with a left and right pleur-X catheter placement in the past. On this presentation, her left pleur-X catheter appeared to be clogged. Preoperative chest radiograph revealed a significant effusion on the left (Figure 1). Computed tomography furthered revealed a complex, loculated effusion on the left (Figure 2). A pigtail catheter was placed and we attempted multiple lytic catheter infusions to break up the loculations. This failed and we were concerned that she had developed pulmonary entrapment. She was brought to the operating room for a left VATS decortication that required conversion to an 


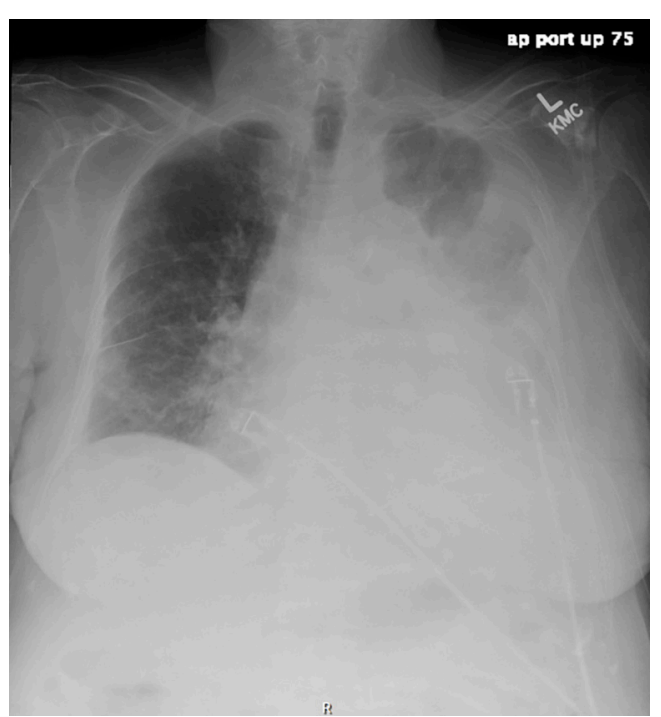

Figure 1 Chest radiograph on presentation with large left sided effusion antero-lateral muscle sparing thoracotomy. She underwent a full lung decortication. Intraoperative findings included a dense fibrous peel that possessed a rubber-like texture. Frozen sections were sent which were negative for malignancy. Pleural fluid character was exudative. Tube thoracostomies were placed and removed postoperatively once deemed appropriate. Her intraoperative fluid cultures were negative for bacterial or fungal growth. She was eventually discharged home with pulmonary rehab and supplemental oxygen on postoperative day 6. Hematoxylin and eosin staining demonstrated amorphous material surrounding vessels (Figure 3). Congo Red staining revealed amyloid surrounding vessels (Figure 4) and apply-green birefringence with polarized light (Figure 5) similar to a previous abdominal tissue/omental biopsy. Her outpatient chest radiographs show a significant improvement although there continues to be a small residual effusion at the base with blunting of the diaphragmatic angle (Figure 6).
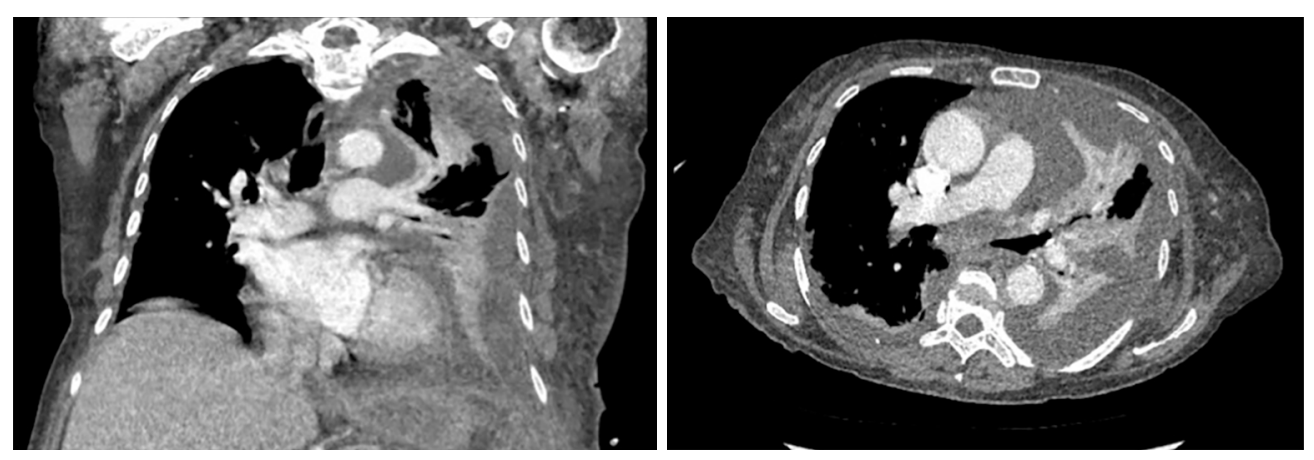

Figure 2 CT chest demonstrating collapse left lung with complex, loculated effusion and possible pulmonary entrapment. CT, computed tomography.
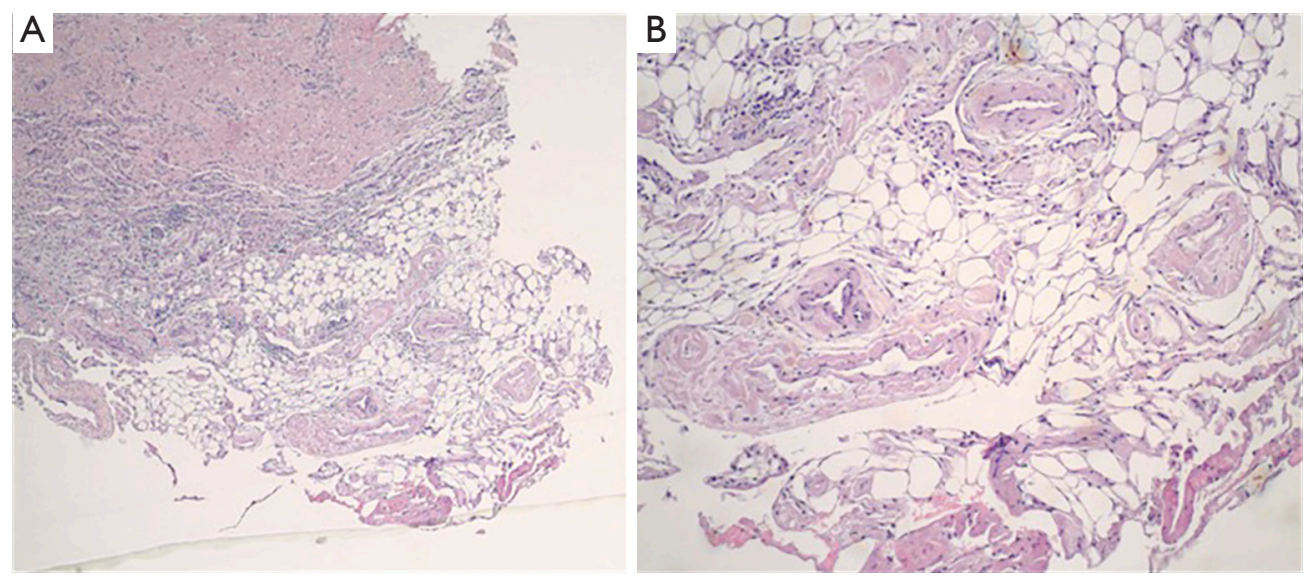

Figure $3 \mathrm{H} \& \mathrm{E}$ demonstrating pink amorphous material surrounding vessels in fat (A. 40x; B. 100x). 

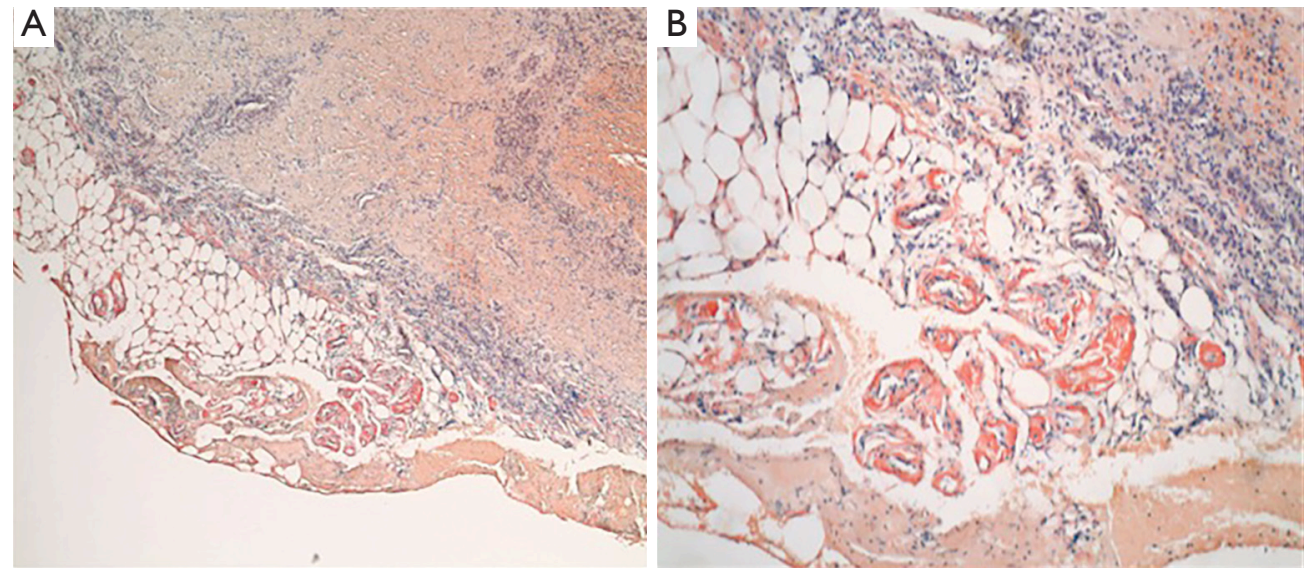

Figure 4 Congo red stain showing amyloid surrounding vessels [A. low power (40x); B. high power (100x)].
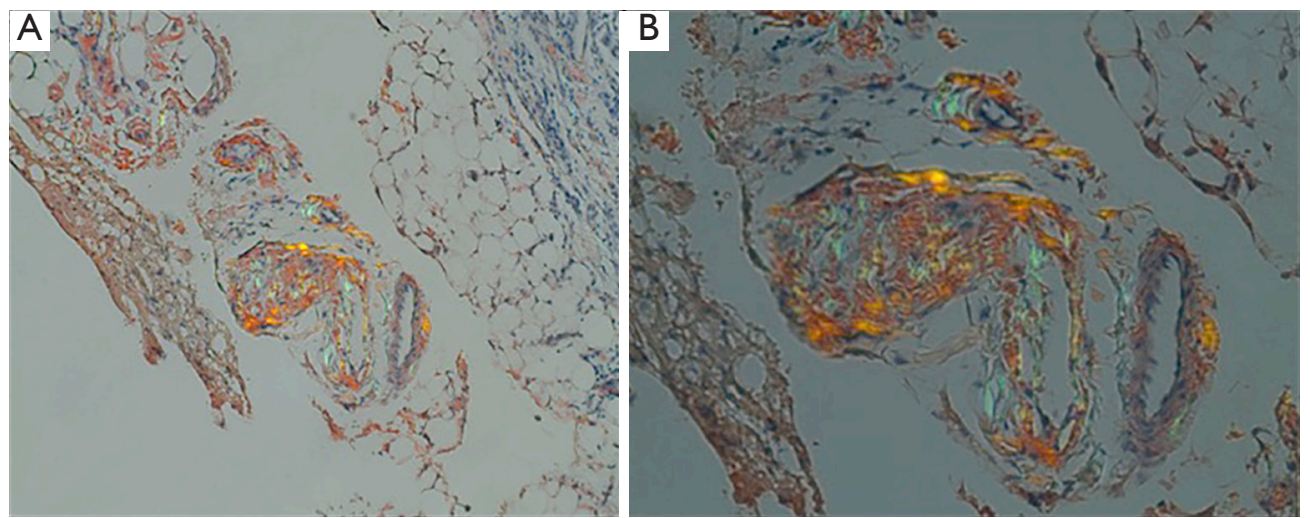

Figure 5 Amyloid stained with Congo red showing apple-green birefringence in polarized light (amyloid surrounding blood vessels. (A) Intermediate power (100x); (B) high power (200x).

\section{Discussion}

In an effort to discover the cause of these persistent pleural effusions associated with amyloidosis of the pleura, Berk et al. reviewed their experience of 636 patients with AL type amyloidosis (2). They found 35 (6\%) with persistent pleural effusions requiring multiple large volume thoracocentesis and aggressive diuresis. They compared this group to 120 patients with cardiac AL amyloidosis without pleural effusions. They performed extensive tissue biopsies as well as echocardiographic comparisons between groups and failed to find an obvious difference contributing to pleural effusions. They concluded that AL amyloid deposits in the pleural cavity could possibly result in direct disruption of pleural function. To date, no clear mechanism has been described, however experts in the field believe the process is secondary to an underlying lymphoproliferative disorder.
Pathological evaluation by Khoor et al. found that pleural involvement correlated to pleural effusions (3). At the histological level, the pulmonary architecture appeared preserved. Khoor et al. notes that under closer inspection, the alveolar septa were thickened with eosinophilic infiltration involving the walls with small nodules from amyloid deposition.

Since 2003, there have been several case reports of persistent pleural effusions found to be secondary to amyloid deposition in the pleural space (4-10). Thus far, the largest series reported is from Berk et al. (2) who published a median survival time of 1.8 months in untreated patients with persistent pleural effusions. With intensive chemotherapy and autologous stem cell transplantation, survival increased to 21.8 months. To our knowledge, the surgical treatment of this disease has not been clarified. 


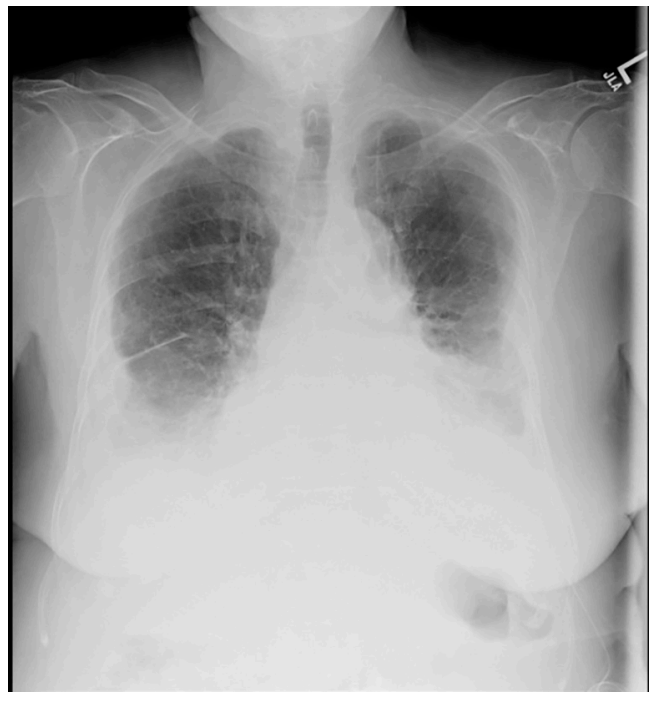

Figure 6 Follow-up chest radiograph demonstrated near resolution of effusion and improved expansion of the left lung.

We performed a full lung decortication with hope for reexpansion and to promote symphysis between the visceral and parietal pleura. Some groups have performed VATS talc pleurodesis to prevent further effusions $(9,10)$. However, talc is not commonly used in today's practice.

\section{Conclusions}

Although persistent pleural effusions secondary to systemic amyloidosis are rare, it should be on the differential list of pleural disease. At this time, the mechanism of pleural disruption from amyloid deposition is theoretical, as other studies have shown no correlation of pleural amyloid deposits when there is cardiac involvement. Continued investigation of this disease process is warranted as it carries a significantly poor prognosis.

\section{Acknowledgments}

Funding: None.

\section{Footnote}

Conflicts of Interest: All authors have completed the ICMJE uniform disclosure form (available at http://dx.doi. org/10.21037/ccts.2019.05.03). The authors have no conflicts of interest to declare.
Ethical statement: The authors are accountable for all aspects of the work in ensuring that questions related to the accuracy or integrity of any part of the work are appropriately investigated and resolved. Informed written consent was obtained from the patient's power of attorney and health care proxy to publish their care, investigations, and treatment. All efforts to remove patient health information and maintain anonymity were made. Informed written consent was obtained from the patient's power of attorney and health care proxy to publish their care, investigations, and treatment. All efforts to remove patient health information and maintain anonymity were made.

Open Access Statement: This is an Open Access article distributed in accordance with the Creative Commons Attribution-NonCommercial-NoDerivs 4.0 International License (CC BY-NC-ND 4.0), which permits the noncommercial replication and distribution of the article with the strict proviso that no changes or edits are made and the original work is properly cited (including links to both the formal publication through the relevant DOI and the license). See: https://creativecommons.org/licenses/by-nc-nd/4.0/.

\section{References}

1. Quock TP, Yan T, Chang E, et al. Epidemiology of AL amyloidosis: a real-world study using US claims data. Blood Adv 2018;2:1046-53.

2. Berk JL, Keane J, Seldin DC, et al. Persistent pleural effusions in primary systemic amyloidosis: etiology and prognosis. Chest 2003;124:969-77.

3. Khoor A, Colby TV. Amyloidosis of the Lung. Arch Pathol Lab Med 2017;141:247-54.

4. Coolbear F, Bilawich AM, Tongson J, et al. Pleural amyloidosis imitating pleural malignancy. Respir Med Case Rep 2017;20:195-7.

5. Nakano T, Endo S, Tetsuka K, et al. Asymptomatic localized pleural amyloidosis mimicking malignant pleural mesothelioma: report of a case. J Thorac Dis 2016;8:E157-60.

6. George S, Ravindran M, Anandan PT, et al. Primary systemic amyloidosis: A rare cause for pleural effusion. Respir Med Case Rep 2014;13:39-42.

7. Mansalis KA, Klein DA, Demartini SD, et al. Pleural findings in a patient with persistent pulmonary effusions from systemic amyloidosis. Amyloid 2011;18:29-31. 
8. Schwarz D, Jue C, Sikov W. Primary systemic amyloidosis and persistent pleural effusions. Amyloid 2009;16:239-42.

9. Briggs JH, Singleton WG, Burke MM, et al. Amyloidosis presenting as bilateral transudative pleural effusions with normal cardiac investigations: a case report. Cases J

doi: $10.21037 /$ ccts.2019.05.03

Cite this article as: Tran A, Blutreich AM, McKelvey A. Pleural amyloidosis presenting as recurrent bilateral pleural effusions. Curr Chall Thorac Surg 2019;1:5.
2009;2:6963.

10. Bontemps F, Tillie-Leblond I, Coppin MC, et al. Pleural amyloidosis: thoracoscopic aspects. Eur Respir J 1995;8:1025-7. 